\title{
Surgical Treatment of Central Giant Cells Lesions in the Maxilla: Case Report
}

Tratamento cirúrgico de lesão central de células gigantes na maxila: relato de caso

\section{Dmitry José de Santana Sarmento ${ }^{1}$, Jalber Almeida dos Santos ${ }^{2}$, Lúcia Helena Marques de Almeida Lima ${ }^{3}$, Marcelino Guedes de Lima ${ }^{4}$, Gustavo Pina Godoy ${ }^{5}$}

Keywords: granuloma, giant cell, pathology.

Palavras-chave: cirurgia bucal, granuloma de células gigantes, patologia bucal.

\section{INTRODUÇÃO}

A lesão central de células gigantes (LCCG) consiste em um processo proliferativo benigno nãoneoplásico, o qual corresponde a cerca de $7 \%$ das lesões de maxila. Apresenta maior acometimento em adultos jovens e crianças, com predileção pelo gênero feminino, na proporção de 2:1 em relação ao masculino ${ }^{1-3}$

A LCCG é normalmente assintomática, seu comportamento clínico pode ser ou não agressivo. Na maxila, essa lesão pode invadir o assoalho do seio maxilar, a órbita e/ou as fossas nasais. Destacase ainda que pode se observar assimetria facial, desvio nasal e mobilidade dos elementos dentais associados ${ }^{1,}$

Tais lesões apresentam etiopatogenia obscura, diferentes apresentações clínicas e diversas modalidades de tratamento ${ }^{2}$. Radiograficamente apresenta aspecto radiolúcido uni ou multilocular, com bordas definidas, podendo ou não apresentar expansão cortical e deslocamento dental ${ }^{3}$.

As hipóteses diagnósticas a serem consideradas dependem do grau de agressividade, rapidez de desenvolvimento, presença de características inflamatórias, dor, mobilidade dental e outras manifestações. Como diagnósticos diferenciais destacam-se a Lesão Periférica de Células Gigantes, o Cisto Ósseo Aneurismático e o Tumor Marrom do Hiperparatireoidismo

A LCCG dos maxilares apresenta histologicamente células gigantes multinucleadas bem como células mononucleadas arredondadas, ovaladas e fusiformes, dispersas em tecido conjuntivo fibroso com focos hemorrágicos e vascularizacão abundante

Os principais meios de tratamento são: a biopsia excisional, a curetagem com margem de segurança e a resseccão parcial ou total do osso afetado; o uso de corticosteroides injetáveis na região acometida vem sendo utilizado com êxito ${ }^{1,5}$.

E necessário tratamento suporte a base de antibióticos, analgésicos e corticosteroides por um

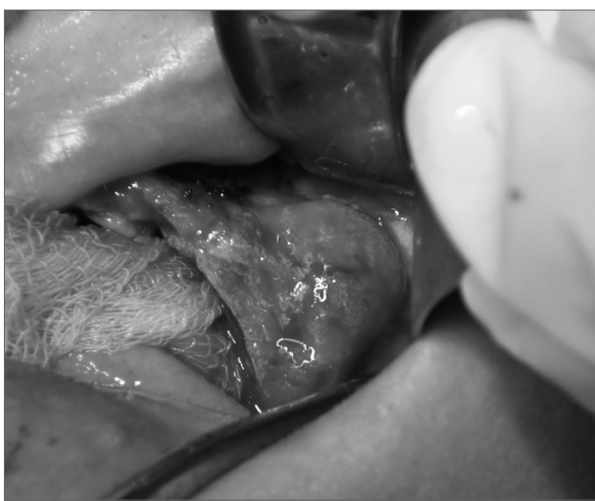

Figura 1. Tratamento Cirúrgico de Lesão Central de Células Gigantes na Maxila: Relato de Caso - Aspecto cirúrgico da lesão. período médio de 10 dias após cirurgia, assim como a necessidade de acompanhamento pós-operatório e exames radiográficos para avaliar a evolução do caso $^{1}$.

Portanto, pondo em relevância os aspectos abordados, destaca-se o objetivo de descrever um caso clínico de LCCG, enfatizando seus procedimentos clínicos, radiográficos e laboratoriais para diagnóstico, e tratamento cirúrgico eleito.

\section{RELATO DO CASO CLÍNICO}

A paciente de 33 anos, gênero feminino, leucoderma, procurou o Servico de Cirurgia e Traumatologia Buco-maxilo-facial do Hospital Pedro I em Campina Grande-PB, afirmando que a prótese total perdera estabilidade, e relatando aumento de volume no lado esquerdo da maxila. Na história clínica, a paciente acreditava que o aumento na região estaria associado à remoção recente de elemento dentário, que a mesma complementou ter sido bastante traumática.

Ao realizar o exame físico extrabucal, não se observaram alterações do padrão de normalidade. No exame físico intrabucal verificou-se aumento de volume na região de maxila esquerda, com expansão das corticais ósseas. À palpacão a lesão apresentou consistência dura com crescimento intra-ósseo.

$\mathrm{Na}$ radiografia panorâmica e tomografia computadorizada, foi observada uma massa radiopaca com imagens radiolúcidas. Foi realizada a excisão cirúrgica da lesão com curetagem meticulosa, optou-se em delinear uma margem de segurança para melhor prognóstico, destacando-se que todo procedimento foi realizado em ambiente hospitalar (Figur 1), e que o mesmo se deu posteriormente à biópsia incisional em ambulatório. A peça foi enviada para exame histopatológico onde se observou diagnóstico conclusivo de LCCG. A conduta terapêutica consistiu na utilização de Amoxicilina 500mg (antibiótico) administrando 1 cápsula via oral (VO) de $8 / 8$ horas (h), Dipirona 500mg (analgésico) - 1 comprimido (comp.) VO de $6 / 6$ h e Dexametasona $0,75 \mathrm{ml}$ (corticosteroide) 1 comp. VO de 12/12h.

Os cortes histológicos revelaram fragmentos de tecido conjuntivo exibindo duas populações celulares (mononucleadas e multinucleadas). As células mononucleares exibiam morfologia fusiforme com núcleos alongados e citoplasma claro. As células gigantes multinucleadas destacavam-se por apresentar uma quantidade variável de núcleos e amplo citoplasma de coloração eosinofílica.

A paciente foi acompanhada por um período de um mês, sendo remarcada para consultas rotineiras de proservação durante 6 meses, apresentando evolução satisfatória do pós-operatório.

\section{DISCUSSÃO}

Ahmed et al. ${ }^{2}$ e Ciorba et al. ${ }^{6}$ afirmaram que a LCCG é mais comum em pacientes do gênero femi- nino com idade inferior a 30 anos, fato reforçado pelo relato aqui descrito. Apesar de a principal localização da LCCG, ser na mandíbula ${ }^{1,3}$ no caso clínico a lesão apresentou-se na maxila, localização esta destacada por Uzbek; Mushtaq 5 . Güngörmüs; Akgül $^{3}$ afirmaram que $22 \%$ dos pacientes com LCCG eram edêntulos totais, característica também observada na paciente objeto do presente relato.

Ainda não se sabe ao certo a etiologia das LCCG, porém alguns fatores, como o trauma e exodontias múltiplas, podem estar ligados a essa patologia ${ }^{1,5}$, o que foi possível ser observado na anamnese do caso ora descrito.

A paciente apresentava quadro assintomático, ausência de sangramento, presença de abaulamento das corticais, ligeira assimetria facial, sendo a lesão palpável ao exame intrabucal, características observadas em relatos como os de Neville et al. ${ }^{4} \mathrm{e}$ Ciorba et al. ${ }^{6}$.

As características histopatológicas da LCCG geralmente são representadas por populações de células mononucleadas e multinucleadas que podem estar acompanhadas por infiltrado inflamatório ${ }^{2-4}$ estando de acordo com as observadas no estudo histopatológico da peça removida do caso.

A cirurgia é o método mais tradicional e aceito para o tratamento da LCCG ${ }^{5,6}$, sendo utilizado para o caso através da excisão cirúrgica da lesão, com curetagem meticulosa para diminuir o risco de recidiva, conduta realizada também por Tasar et al. Uzbek e Mushtaq ${ }^{5}$. Foi associado ao tratamento o uso de corticosteroides, analgésicos e antibióticos, com intuito de atenuar os efeitos pós-operatórios e otimizar o prognóstico.

\section{CONCLUSÃO}

A LCCG é uma patologia pouco frequente e de etiologia obscura que, apesar de benigna, pode ser altamente destrutiva. Seu diagnóstico conclusivo depende do exame histopatológico, e o tratamento de eleicão deve ser criteriosamente elaborado de acordo com as peculiaridades de cada caso.

\section{REFERÊNCIAS BIBLIOGRÁFICAS}

1. Tasar F, Bayik S, Eratalay K. Unusual localization an etiology of giant cell granuloma. J Islam Acad Scienc $1991 ; 4: 190-2$

2. Ahmed S, Babu I, Priya SP. Central giant cell granulom - a case report. J Oral Maxillofac Pathol.2003;7:111-4.

3. Güngörmüs M, Akgül HM. Central Giant Cell Granuloma of the Jaws: A Clinical and Radiologic Study. J Contemp Dent Pract.2003:4:387-97.

4. Neville BW, Damm DD, Allen CM, Bouquot JE. Patologia oral e maxilofacial. 3.ed. Rio de Janeiro: Elsevier 2009

5. Uzbek UH, Mushtaq I. Giant cell granuloma of the maxilla. J Ayub Med Coll Abbottabad.2007;19:393-5.

6. Ciorba A, Altissimi G, Giansanti M. Giant cell granuloma of the maxilla: case report. Acta Otorhinolaryngol Ital. 2004:24:26-9.

Mestrando em Patologia Oral pela UFRN.

${ }^{2}$ Mestrando em Odontologia pela UEPB.

${ }^{3}$ Doutorando em ciências e engenharia de materiais, Professora Titular da UEPB.

${ }^{4}$ Doutorando em ciências e engenharia de materiais, Professor Titular da UEPB.

${ }^{5}$ Doutor em Patologia Oral pela UFRN, Professor Titular de Patologia Oral da UEPB.

Endereço para correspondência: Dmitry José de Santana Sarmento - Rua José Jesuino de Brito 415 Quarenta Campina Grande PB 58.416-270.

Este artigo foi submetido no SGP (Sistema de Gestão de Publicações) da BJORL em 13 de dezembro de 2009. cod. 6838

Artigo aceito em 23 de março de 2010 